\title{
Adubação foliar com níquel e molibdênio no feijoeiro comum cv. Ouro Vermelho ${ }^{1}$
}

\author{
José Francisco Lopes ${ }^{2}$, Fábio Cunha Coelho ${ }^{3}$, Otacílio José Passos Rangel ${ }^{4}$, Wanderson Souza Rabello ${ }^{5}$, \\ Geraldo de Amaral Gravina ${ }^{6}$, Henrique Duarte Vieira
}

\begin{abstract}
RESUMO
O objetivo deste trabalho foi avaliar o efeito da aplicação foliar de níquel (Ni) e molibdênio (Mo) sobre componentes de rendimento, crescimento e composição mineral do feijoeiro comum Ouro Vermelho. O delineamento experimental foi o de blocos casualizados, com quatro repetições e arranjo fatorial 5 x 2, constituído de doses de Ni ( $0,15,30,45$ e 60 $\left.\mathrm{g} \mathrm{ha}^{-1}\right)$ e de Mo (0 e $\left.80 \mathrm{~g} \mathrm{ha}^{-1}\right)$, aplicadas por via foliar, aos 25 dias após a semeadura, na forma de cloreto de níquel hexaidratado e de molibdato de amônio, respectivamente. As doses de Ni não influenciaram os teores foliares de N, P, $\mathrm{K}, \mathrm{Fe}, \mathrm{Mo} \mathrm{e} \mathrm{Ni}$, aumentaram, porém, os teores de N, Ni e de proteína bruta na semente. A aplicação foliar de Mo reduziu os teores foliares de $\mathrm{P}, \mathrm{Fe}$ e Ni, aumentou, no entanto, o teor foliar de Mo e o teor de N, Mo e de proteína bruta na semente. Observou-se que as doses de Ni e de Mo não afetaram a massa de sementes, o número de sementes por vagem, o número de vagens por planta e a massa seca de raiz do feijoeiro. A aplicação de Mo aumentou em 21,62\% o número de nódulos.
\end{abstract}

Palavras-chave: Phaseolus vulgaris L, cloreto de níquel hexaidratado, molibdato de amônio, micronutrientes.

\section{ABSTRACT}

\section{Foliar fertilization with nickel and molybdenum in common bean cv. 'Ouro Vermelho'}

The objective of this work was to assess the effect of foliar application with nickel (Ni) and molybdenum (Mo) on components of yield, growth and mineral composition of common bean cv. 'Ouro Vermelho'. The experiment was arranged in a randomized block design with four replications in a 5 x 2 factorial scheme consisted of rates of $\mathrm{Ni}(0,15,30$, 45 and $\left.60 \mathrm{~g} \mathrm{ha}^{-1}\right)$, and $\mathrm{Mo}\left(0\right.$ and $\left.80 \mathrm{~g} \mathrm{ha}^{-1}\right)$ applied in the leaves 25 days after seeding. The elements were applied in the form of Ni chloride hexahydrate and ammonium molybdate. The foliar application of Ni did not change the foliar contents of N, P, K, Fe, Mo and Ni, but increased the content of N, Ni and the crude protein in the seed. The application of Mo decreased the foliar contents of $\mathrm{P}, \mathrm{Fe}$ and $\mathrm{Ni}$, but increased the foliar content of Mo and the content of $\mathrm{N}$, Mo and crude protein in the seed. It was found that the foliar application of Ni and Mo did not affect the seed weight, the number of beans per pod, the number of pod per plant and the dry weight of the root system. The application of Mo increased in $21.62 \%$ the number of nodules.

Key words: Phaseolus vulgaris L, chloride of nickel hexahydrate, ammonium molybdate, micronutrients.

\footnotetext{
Recebido para publicação em 04/03/2013 e aprovado em 09/08/2013.

${ }^{1}$ Este trabalho é parte da tese de doutorado do primeiro autor.

${ }^{2}$ Licenciado em Ciências Agrícolas, Mestre. Laboratório de Fitotecnia, Universidade Estadual Norte Fluminense Darcy Ribeiro, Campus dos Goytacazes, Avenida Alberto Lamego, 2000, Parque Califórnia, 28013-602, Campos dos Goytacazes, Rio de Janeiro, Brasil. jflzito@ hotmail.com (autor para correspondência).

${ }^{3}$ Engenheiro-Agrônomo, Doutor. Laboratório de Fitotecnia, Universidade Estadual Norte Fluminense Darcy Ribeiro, Campus dos Goytacazes, Avenida Alberto Lamego, 2000, Parque Califórnia, 28013-602, Campos dos Goytacazes, Rio de Janeiro, Brasil. fcoelho@uenf.br

${ }^{4}$ Engenheiro-Agrônomo, Doutor. Instituto Federal de Educação, Ciência e Tecnologia do Espírito Santo, Campus de Alegre, Fazenda Caixa d ' água, Rive, 29500-000, Alegre, Espírito Santo, Brasil. ojprangel@ifes.edu.br

${ }_{5}^{5}$ Engenheiro-Agrônomo, Mestre. Laboratório de Engenharia Agrícola, Universidade Estadual Norte Fluminense Darcy Ribeiro, Campus dos Goytacazes, Avenida Alberto Lamego, 2000, Parque Califórnia, 28013-602, Campos dos Goytacazes, Rio de Janeiro, Brasil. rabellosouza@ hotmail.com

${ }^{6}$ Engenheiro-Agrônomo, Doutor. Laboratório de Engenharia Agrícola, Universidade Estadual Norte Fluminense Darcy Ribeiro, Campus dos Goytacazes, Avenida Alberto Lamego, 2000, Parque Califórnia, 28013-602, Campos dos Goytacazes, Rio de Janeiro, Brasil. gravina@uenf.br

${ }^{7}$ Engenheiro-Agrônomo, Doutor. Laboratório de Fitotecnia, Universidade Estadual Norte Fluminense Darcy Ribeiro, Campus dos Goytacazes, Avenida Alberto Lamego, 2000, Parque Califórnia, 28013-602, Campos dos Goytacazes, Rio de Janeiro, Brasil. henrique @uenf.br
} 


\section{INTRODUÇÃO}

O feijoeiro tem especial importância para a agricultura brasileira, por sua relevância na dieta da população, e por ser o país um dos maiores produtores e consumidores de feijão do mundo (Barbosa et al., 2010). Apesar disto, a produtividade média observada é baixa. Na última década, ficou em torno dos $850 \mathrm{~kg} \mathrm{ha}^{-1}$ (Conab, 2012). Um dos fatores que tem contribuído para essa realidade é a negligência quanto à nutrição mineral da cultura (Leal e Prado, 2008; Biscaro et al., 2011), principalmente no que diz respeito aos micronutrientes. Para Guareschi e Perin (2008), a produção agrícola brasileira dependerá cada vez mais do uso de micronutrientes, buscando corrigir sua deficiência e aumentar sua eficiência.

Na cultura do feijoeiro, o molibdênio (Mo) é um dos micronutrientes que tem despertado grande interesse, principalmente em função dos resultados que vêm sendo obtidos com a adubação molíbdica foliar (Silva et al., 2003). É considerado um elemento essencial para as plantas, por ser componente das enzimas redutase do nitrato e nitrogenase. Sua carência pode afetar o metabolismo do $\mathrm{N}$ e apresenta-se como das possíveis causas da baixa produtividade da cultura do feijão (Pessoa et al., 2000).

Segundo Pires et al. (2002), as respostas das plantas à aplicação de Mo têm-se mostrado variáveis entre as espécies e, mesmo, entre os cultivares da mesma espécie, em consequência das variações na capacidade de absorção, translocação, acúmulo nos tecidos e utilização do nutriente pela planta. De qualquer forma, em diversos trabalhos, observa-se aumento de produtividade do feijoeiro com o fornecimento de molibdênio (Ferreira et al., 2003; Fernandes et al., 2005; Calonego et al., 2010; Rocha et al., 2011). As doses utilizadas têm variado em torno de $80 \mathrm{~g} \mathrm{ha}^{-1}$ de Mo (Pessoa et al., 2000; Ferreira et al., 2003; Nascimento et al., 2009; Calonego et al., 2010) e a melhor época de aplicação situa-se em torno de 25 dias após emergência (DAE) (Pessoa et al., 2001; Ferreira et al., 2002; Calonego et al., 2010).

O Níquel (Ni) é outro micronutriente extremamente importante para o metabolismo do nitrogênio (Jasmim et al., 2002) e, portanto, capaz de afetar a produtividade das fabáceas. É componente da urease, enzima que atua na hidrólise da ureia (Dixon et al., 1975), e influencia a enzima hidrogenase, que aumenta a eficiência da fixação de nitrogênio em fabáceas (Klucas et al., 1983). Entretanto, a literatura carece de trabalhos com Ni. Em trabalho realizado por Campanharo (2010), a autora observou que as doses de Ni utilizadas não afetaram o crescimento, porém reduziram o teor de manganês (Mn) do feijoeiro.

Considerando-se a importância do Ni e do Mo para a cultura do feijoeiro, realizou-se este trabalho com o objetivo de avaliar a influência do Ni e do Mo sobre os componentes de rendimento, crescimento e composição mi- neral do feijoeiro comum (Phaseolus vulgaris L.) cv. Ouro Vermelho.

\section{MATERIAIS E MÉTODOS}

O experimento foi conduzido em casa de vegetação, no Instituto Federal de Educação, Ciência e Tecnologia do Espírito Santo, campus de Alegre, localizado no distrito de Rive, Alegre-ES, no período de março a junho de 2011. O solo utilizado foi classificado como Argissolo Acinzentado distrófico.

O delineamento experimental foi o de blocos casualizados, com quatro repetições e fatorial 5 x 2, constituído das combinações doses de $\mathrm{Ni}\left(0,15,30,45\right.$ e $\left.60 \mathrm{~g} \mathrm{ha}^{-1}\right)$, e Mo (0 e $\left.80 \mathrm{~g} \mathrm{ha}^{-1}\right)$, aplicadas por via foliar, aos 25 dias após a semeadura, na forma de cloreto de Ni hexaidratado e molibdato de amônio, respectivamente. A unidade experimental foi constituída por um vaso com capacidade de $10 \mathrm{dm}^{3}$, com duas plantas. Utilizou-se, para cada vaso, uma réplica, a fim de que, na época do florescimento, fosse avaliado o número de nódulos, bem como coletadas folhas para as determinações dos nutrientes. O segundo vaso possibilitou a colheita das sementes e as avaliações das vagens e plantas.

O solo utilizado (Tabela 1) foi coletado na camada de 0,0 a 20,0 cm de profundidade, destorroado e passado em peneira de $6 \mathrm{~mm}$ de diâmetro, sendo a adubação feita de acordo com as recomendações de Oliveira et al. (1991), e consistiu na aplicação, por vaso, de $3 \mathrm{~g}$ de calcário dolomítico, 2,22 g de ureia, 2,5 g de cloreto de potássio e $12,81 \mathrm{~g} \mathrm{vaso}^{-1}$ de FH 450, composto por $24 \%$ de fósforo total, $11 \%$ de fósforo solúvel em ácido cítrico, $25 \%$ de cálcio e $4 \%$ de enxofre.

Foram utilizadas sementes de feijoeiro comum (Phaseolus vulgaris L.) cv. Ouro Vermelho, inoculadas com bactérias do gênero Rhizobium tropici, utilizando-se o inoculante turfoso Masterfix Feijão (SEMIA 4080), com 5 x $10^{9}$ bactérias por grama, na dosagem de $150 \mathrm{~g} / 50 \mathrm{~kg}$ de sementes. A semeadura foi realizada no dia 20/03/2011 utilizando-se dez sementes por vaso. Dez dias após a semeadura (DAS), foi feito o desbaste, mantendo-se duas plantas vigorosas em cada vaso. Os vasos foram irrigados diariamente, visando a manter a umidade do solo adequada para o bom crescimento e desenvolvimento das plantas.

No estádio de desenvolvimento V4, aos 25 DAS, as doses de Ni e Mo foram aplicadas, por via foliar, por meio de um borrifador manual, visando a molhar as folhas completamente, mas evitando o escorrimento.

No início do florescimento, aos 40 DAS, as plantas de um vaso foram colhidas e separadas em folhas, ramos, raízes e nódulos. Na colheita, amostras de $100 \mathrm{~g}$ de sementes do outro vaso também foram obtidas para análise dos teores de N, Fe, Mo e Ni nas sementes. As folhas, raízes e as

Rev. Ceres, Viçosa, v. 61, n.2, p. 234-240, mar/abr, 2014 
sementes foram secadas em estufa com ventilação forçada, a $65^{\circ} \mathrm{C}$, durante 72 horas. Posteriormente, folhas e sementes foram moídas em moinho tipo Willey, usando-se peneira de 20 mesh, e acondicionadas em recipientes plásticos herméticos, para posterior determinação dos teores de N, P, $\mathrm{K}, \mathrm{Fe}, \mathrm{Mo}$ e Ni. As raízes foram pesadas, para a determinação da massa seca e os nódulos radiculares, cuidadosamente separados das raízes, foram contados. A partir do teor de $\mathrm{N}$ na semente, foi calculada a percentagem de proteína na semente, empregando-se o fator 6,25.

A determinação do teor de $\mathrm{N}$ total foi realizada a partir da digestão sulfúrica $0,1 \%$ (Malavolta et al., 2006). Os teores de $\mathrm{P}, \mathrm{K}$ e Fe foram obtidos a partir da digestão nítrico-perclórica (Tedesco et al., 1985) e, os teores de $\mathrm{Ni}$ e Mo, por digestão por via seca, em mufla, a $550^{\circ} \mathrm{C}$. O $\mathrm{N}$ total foi determinado pelo método de Kjeldahl (Malavolta et al., 1997); o P foi determinado por espectrofotometria; pelo método da vitamina $\mathrm{C}$, modificado por Braga e Defelipo (1974); o K, por fotometria de chama e, o Fe, por espectrofotometria de absorção atômica, enquanto o Mo e Ni foram determinados por espectrofotometria de absorção atômica com forno de grafite (Bataglia et al., 1983).

Por ocasião da colheita, obteve-se a altura das plantas, número de vagens por planta, o número de sementes por vagem e a massa das sementes.

Os dados obtidos foram submetidos à análise de variância. As comparações entre as médias de adubação molíbdica foram feitas pelo teste $\mathrm{F}$, a $5 \%$ de probabilidade, e os efeitos de doses de Ni foram estudados por meio de análise de regressão, sendo os modelos escolhidos segundo os melhores ajustes, confirmados pelos maiores valores dos coeficientes de determinação $\left(R^{2}\right)$, pela significância dos coeficientes de regressão e do teste $\mathrm{F}$ da regressão, ambos até $5 \%$ de probabilidade.

\section{RESULTADOS E DISCUSSÃO}

Os teores de $\mathrm{N}$ e K na folha não foram influenciados pela aplicação de Mo (Tabela 2) e situaram-se dentro da faixa adequada, proposta por Malavolta (1997). De forma semelhante, Nascimento et al. (2004) não verificaram efeito do Mo sobre o teor de N nas folhas do feijoeiro. Quanto ao $\mathrm{K}$, os resultados obtidos discordam dos obtidos por
Ferreira et al. (2002) e Pires et al. (2005), que verificaram que o Mo aumentou o teor de K do feijoeiro. Quanto ao efeito do $\mathrm{Ni}$, as doses aplicadas não influenciaram significativamente $(\mathrm{p}<0,05)$ os teores de $\mathrm{N}$ e de K. Entretanto, Campanharo (2010) observou que doses de até $100 \mathrm{~g} \mathrm{ha}^{-1}$ de Ni reduziram o teor de $\mathrm{N}$, mas não alteraram o teor de $\mathrm{K}$ do feijoeiro. Vale ressaltar que a dose máxima utilizada neste trabalho foi de $60 \mathrm{~g} \mathrm{ha}^{-1} \mathrm{de} \mathrm{Ni}$.

Observou-se que a adubação foliar com $80 \mathrm{~g} \mathrm{ha}^{-1} \mathrm{de}$ Mo reduziu os teores de $\mathrm{P}$, Fe e Ni e aumentou consideravelmente o teor de Mo nas folhas do feijoeiro (Tabela 2). O P foi o nutriente que apresentou redução mais expressiva $(18,7 \%)$, seguido do $\mathrm{Ni}(18,4 \%)$ e do Fe $(7,7 \%)$. Diferentemente do observado neste trabalho, Ferreira et al. (2002) observaram que doses de até $120 \mathrm{~g} \mathrm{ha}^{-1}$ de Mo proporcionaram maiores teores de $\mathrm{P}, \mathrm{S}, \mathrm{Ca}, \mathrm{Mg}$ e $\mathrm{K}$ nas folhas do feijoeiro. Por outro lado, o resultado com o Mo corrobora os obtidos por Pessoa et al. (2000), Ferreira et al. (2003), Pires et al. (2005) e Rocha et al. (2011). As doses de Ni não influenciaram significativamente $(\mathrm{p}<0,05)$ os teores foliares de N, P, K, Fe, Ni e Mo.

Os teores de $\mathrm{N}$ e de proteína na semente apresentaram resposta linear à aplicação das doses de Ni (Figuras 1 e 2). Entretanto, o incremento máximo observado $(8,07 \%)$ foi pequeno. De qualquer forma, possivelmente o aumento no teor de $\mathrm{N}$ e de proteína na semente seja consequência de uma maior atividade enzimática da urease, proporcionada pelo Ni. Além disso, a influência do Ni no complexo enzimático hidrogenase, aumentando a eficiência da fixação de nitrogênio em leguminosas (Klucas et al., 1983), pode ter contribuído para uma maior acumulação de N.

Quanto ao efeito da aplicação foliar de Mo, pode-se observar, pela Tabela 3, que o Mo aumentou o teor de $\mathrm{N} \mathrm{e}$ de proteína na semente, resultado que corrobora os obtidos por Ferreira et al. (2002), que, estudando o efeito de doses de até $120 \mathrm{~g} \mathrm{ha}^{-1}$ de Mo sobre o feijoeiro, também observaram que esse micronutriente aumentou o teor de $\mathrm{N}$ e de proteína na semente do feijoeiro. Resultados semelhantes foram obtidos por Pessoa et al. (2000) e Kubota et al. (2008). Possivelmente, o Mo promoveu maior atividade da nitrogenase e redutase do nitrato, possibilitando maior acúmulo de $\mathrm{N}$ e de proteína na semente (Pessoa et

Tabela 1. Características químicas de um Argissolo Acinzentado distrófico. Alegre-ES, 2011

\begin{tabular}{|c|c|c|c|c|c|c|c|c|c|}
\hline pH & $\mathbf{P}$ & $\mathbf{K}$ & $\mathbf{N a}$ & $\mathbf{C a}$ & Mg & Al & $\mathbf{H}+\mathbf{A l}$ & SB & $\mathbf{V}$ \\
\hline$\overline{\mathrm{H}_{2} \mathrm{O}}$ & \multicolumn{3}{|c|}{$\mathrm{mg} \mathrm{kg}^{-1}$} & \multicolumn{5}{|c|}{$\mathrm{cmol}_{\mathrm{c}} \mathrm{dm}^{-3}$} & $\%$ \\
\hline 5,8 & 13 & 86 & 6 & 2,0 & 0,4 & 0,0 & 2,7 & 2,6 & 49 \\
\hline MO & $\mathrm{Zn}$ & $\mathrm{Fe}$ & Mn & Mo & $\mathrm{Ni}$ & $\mathrm{Cu}$ & B & $\mathbf{T}$ & $\mathbf{t}$ \\
\hline $\mathrm{dag} \mathrm{kg}^{-1}$ & \multicolumn{7}{|c|}{$\mathrm{mg} \mathrm{kg}^{-1}$} & \multicolumn{2}{|c|}{$\mathrm{cmol}_{\mathrm{c}} \mathrm{dm}^{-3}$} \\
\hline 1,7 & 7,7 & 89,5 & 92 & 2,2 & 8,4 & 24 & 1,0 & 5,3 & 2,6 \\
\hline
\end{tabular}

Rev. Ceres, Viçosa, v. 61, n.2, p. 234-240, mar/abr, 2014 
al., 2001; Kubota et al., 2008). Vale ressaltar que feijões com maior teor de proteína bruta são associados a feijões de melhor qualidade.

O teor de Mo na semente não foi influenciado, significativamente $(\mathrm{p}<0,05)$, pelas doses de Ni. Porém, como esperado, foi influenciado positivamente pela aplicação do Mo, promovendo um incremento de $315,15 \%$ (Tabela
3). Ferreira et al. (2003), estudando doses de até $120 \mathrm{~g}$ ha${ }^{1}$ de Mo, também observaram que a adubação molíbdica originou sementes com maiores teores de Mo. De acordo com Jacob Neto e Rosseto (1998), boa parte do Mo absorvido é translocado para as sementes.

O Mo é o único micronutriente em relação ao qual, dependendo da espécie, somente sua quantidade na semente

Tabela 2. Teores de N, P, K, Fe, Mo e Ni na folha do feijoeiro comum cv. Ouro Vermelho em resposta à adubação molíbdica. AlegreES, 2011

\begin{tabular}{lcccccc}
\hline $\begin{array}{l}\text { Dose } \\
\mathbf{d e ~ M o}\end{array}$ & $\begin{array}{c}\mathbf{N} \\
(\mathbf{g ~ k g}\end{array}$ & $\begin{array}{c}\mathbf{P} \\
(\mathbf{g ~ k g}\end{array}$ & $\begin{array}{c}\mathbf{K} \\
\left(\mathbf{g ~ k g}^{-1}\right)\end{array}$ & $\begin{array}{c}\mathbf{F e} \\
(\mathbf{m g ~ k g}\end{array}$ & $\begin{array}{c}\mathbf{M o} \\
\left(\mathbf{m g ~ k g}^{-1}\right)\end{array}$ & $\begin{array}{c}\mathbf{N i} \\
\left(\mathbf{m g ~ k g}^{-1}\right)\end{array}$ \\
\hline 0 & $42,73 \mathrm{a}$ & $3,63 \mathrm{a}$ & $2,65 \mathrm{a}$ & $171,73 \mathrm{a}$ & $0,43 \mathrm{~b}$ & $0,76 \mathrm{a}$ \\
80 & $40,12 \mathrm{a}$ & $2,95 \mathrm{~b}$ & $2,47 \mathrm{a}$ & $158,55 \mathrm{~b}$ & $2,13 \mathrm{a}$ & $0,62 \mathrm{~b}$ \\
\hline Média & 41,42 & 3,29 & 2,56 & 165,14 & 1,28 & 0,69 \\
\hline CV(\%) & 9,86 & 20,14 & 11,02 & 8,29 & 25,91 & 16,74 \\
\hline
\end{tabular}

As médias seguidas pelas mesmas letras na coluna não diferem entre si pelo teste $\mathrm{F}$ a $5 \%$ de probabilidade.

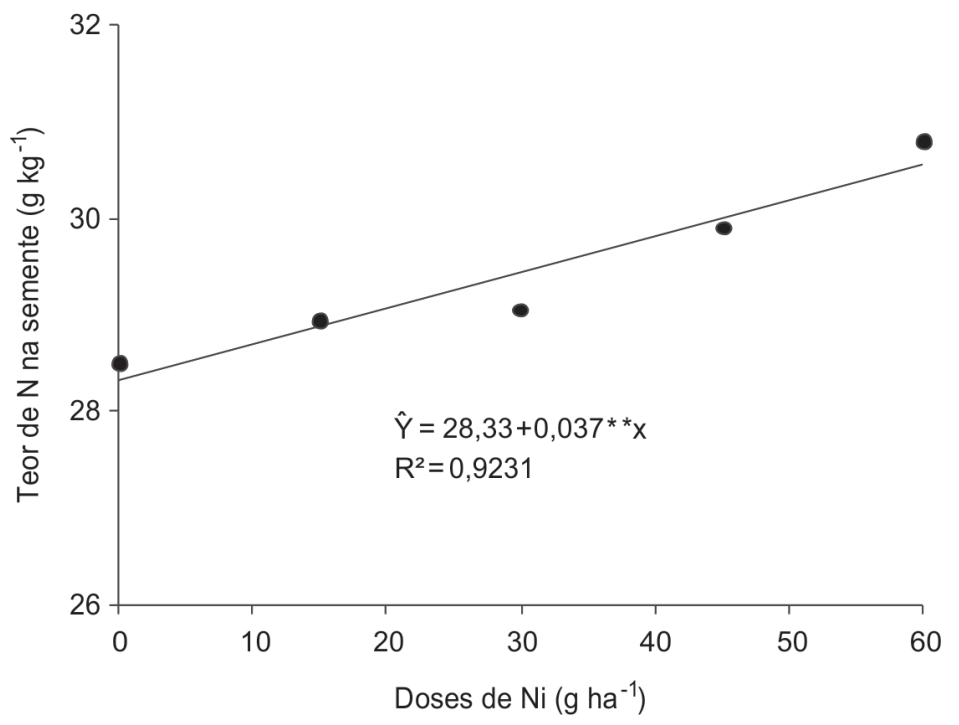

Figura 1. Teor de $\mathrm{N}$ na semente do feijoeiro comum cv. Ouro Vermelho em resposta à adubação com Ni.

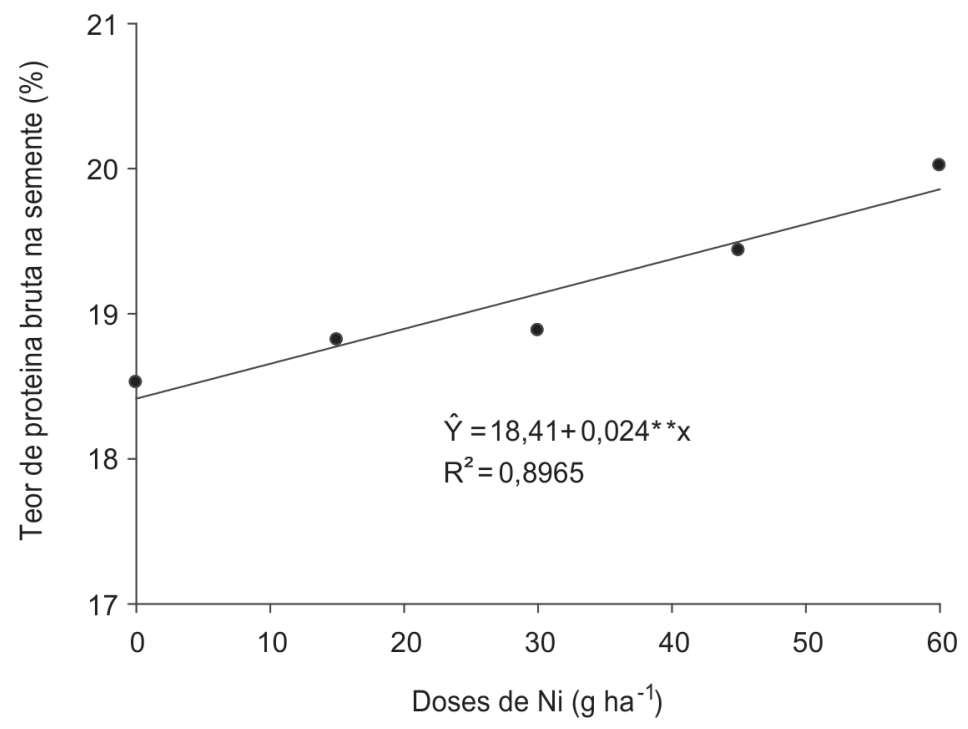

Figura 2. Teor de proteína na semente do feijoeiro comum cv. Ouro Vermelho em resposta à adubação com Ni. 
pode proporcionar o crescimento normal da planta (Malavolta et al., 1997), o que demonstra a importância de se obter sementes com alto teor de Mo. Sementes com alto teor desse elemento estão associadas a uma maior atividade da nitrogenase, maior acúmulo de biomassa e de N, melhor qualidade fisiológica, com maior germinação e maior vigor (Kubota et al., 2008; Leite et al., 2009). Segundo Jacob-Neto e Franco (1986), sementes contendo 3,5 $\mu \mathrm{g}$ semente $^{-1}$ de Mo não requerem adubação suplementar do elemento. Esse conteúdo foi obtido com uma aplicação foliar de $200 \mathrm{~g} \mathrm{ha}^{-1}$ de Mo, parcelada em cinco vezes. Neste trabalho, o conteúdo de Mo das sementes sem adubação molíbdica foi estimado em 2,29 x $10^{-2} \mu \mathrm{g}$ semente $^{-1}$ de Mo, valor bem inferior ao obtido pelos últimos autores.

Houve interação significativa entre os fatores estudados, para o teor de Fe na semente, porém, não foi possível ajustar um modelo de regressão para as doses de Ni. Quanto ao efeito do Mo, observou-se que reduziu o teor de Fe na semente na testemunha e quando foram aplicadas as doses de 15 e $60 \mathrm{~g} \mathrm{ha}^{-1}$ de Ni (Tabela 4).

$\mathrm{O}$ teor de Ni na semente foi influenciado, significativamente, de forma linear, pelas doses de Ni estudadas (Figura 3). Quanto maior a dose de Ni aplicada, maior foi o teor do nutriente na semente. O incremento máximo observado foi de $28,02 \%$, para a maior dose de $\mathrm{Ni}$ aplicada.
Quanto às características de crescimento e componentes de produção, observou-se que as aplicações foliares de Ni e de Mo não afetaram a massa de sementes, o número de sementes por vagem, o número de vagens por planta e a massa seca de raiz do feijoeiro (Tabela 5). Nascimento et al. (2004) e Barbosa et al. (2010), utilizando as mesmas doses de Mo empregadas neste trabalho, também não obtiveram efeito do Mo sobre o número de sementes por vagem, número de vagens por planta e produtividade do feijoeiro. Quanto à massa seca de raiz, os resultados obtidos estão de acordo com os observados por Guareschi e Perin (2008), que também não verificaram influência de doses de até $160 \mathrm{~g} \mathrm{ha}^{-1}$ de Mo sobre a massa seca de raiz do feijoeiro. Campanharo (2010) também não observou efeito sobre a massa seca de raiz do feijoeiro.

O número de nódulos não foi influenciado pelas doses de Ni e Campanharo (2010) também não encontrou esse efeito. No entanto, a adubação com Mo aumentou em 21,62\% o número de nódulos do feijoeiro (Tabela 5). Barbosa et al., (2010) observaram que mesmo sem a utilização de inoculação de sementes com bactérias do gênero Rhizobium, observou-se a presença de nódulos (rizóbio nativo) no sistema radicular das plantas. Os autores constataram que a aplicação de molibdênio pode melhorar a simbiose Rhizobium-feijoeiro, dada sua importância no metabolismo do nitrogênio.

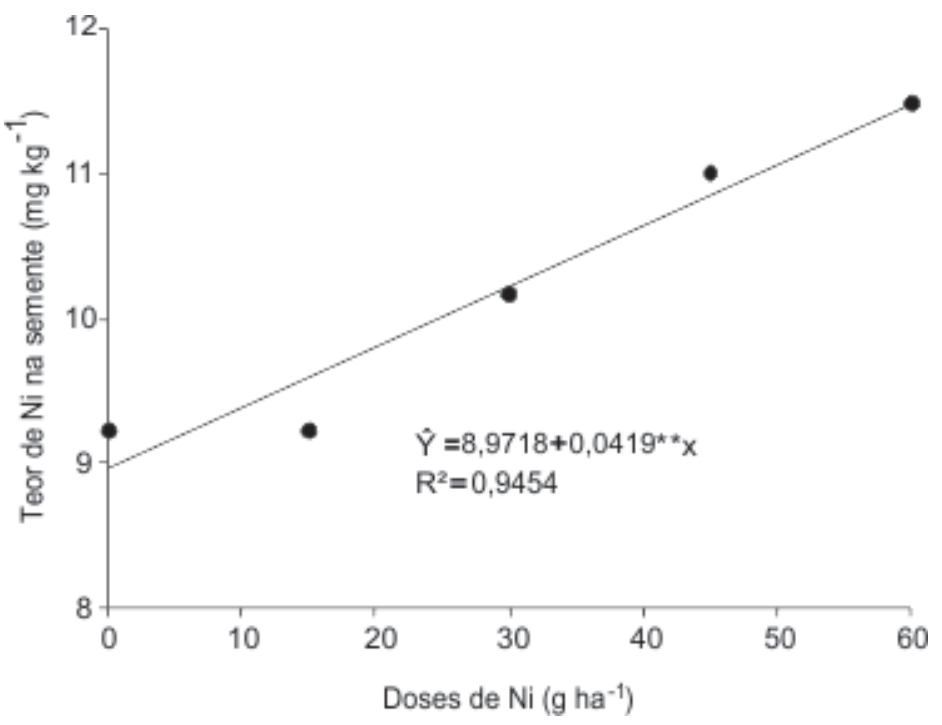

Figura 3. Teor de Ni na semente do feijoeiro comum cv. Ouro Vermelho em resposta à aplicação foliar de doses de Ni.

Tabela 3. Teores de N, Mo e proteína bruta na semente do feijoeiro comum cv. Ouro Vermelho em resposta à adubação molíbdica. Alegre- ES, 2011

\begin{tabular}{lccc}
\hline $\begin{array}{l}\text { Dose } \\
\text { de Mo }\end{array}$ & $\begin{array}{c}\mathbf{N} \\
\left(\mathbf{g ~ k g}^{-1}\right)\end{array}$ & $\begin{array}{c}\text { Mo } \\
\left(\mathbf{m g ~ k g}^{-1}\right)\end{array}$ & $\begin{array}{c}\text { Proteína } \\
(\%)\end{array}$ \\
\hline 0 & $28,18 \mathrm{~b}$ & $0,099 \mathrm{~b}$ & $17,61 \mathrm{~b}$ \\
80 & $30,69 \mathrm{a}$ & $0,312 \mathrm{a}$ & $19,18 \mathrm{a}$ \\
\hline Média & 29,44 & 0,2055 & 19,12 \\
\hline $\mathrm{CV}(\%)$ & 4,39 & 13,66 & 4,75 \\
\hline
\end{tabular}

As médias seguidas pelas mesmas letras na coluna não diferem entre si pelo teste $\mathrm{F}$ a $5 \%$ de probabilidade. 
As doses de Ni estudadas, independentemente da aplicação, ou não, de Mo, não afetaram a altura de plantas. Quanto ao efeito da aplicação foliar de Mo, dentro de cada dose de Ni utilizada, pode-se observar (Tabela 6) que, nas doses de 15 e $30 \mathrm{~g} \mathrm{ha}^{-1}$ de Ni, o Mo aumentou a altura de plantas, ao passo que, na dose de $45 \mathrm{~g} \mathrm{ha}^{-1}$, a aplicação de Mo promoveu redução na altura de plantas.

Tabela 4. Desdobramento da interação Ni x Mo para o teor de Fe na semente do feijoeiro comum cv. Ouro Vermelho, em função da aplicação de Ni e Mo via foliar. Alegre, ES - 2011

\begin{tabular}{lll}
\hline \multirow{2}{*}{$\begin{array}{l}\text { Doses de Ni } \\
\left(\mathbf{g ~ h a}^{-1}\right)\end{array}$} & \multicolumn{2}{c}{ Mo $\left(\mathbf{g ~ h a}^{-1}\right)$} \\
\cline { 2 - 3 } & \multicolumn{2}{c}{$\mathbf{~}$ Fe (mg kg $\left.{ }^{-1}\right)$} \\
\hline 0 & $60,27 \mathrm{a}$ & $\mathbf{8 0}$ \\
\hline 15 & $56,70 \mathrm{a}$ & $51,37 \mathrm{~b}$ \\
30 & $50,92 \mathrm{a}$ & $52,45 \mathrm{a}$ \\
45 & $51,60 \mathrm{a}$ & $49,35 \mathrm{a}$ \\
60 & $57,95 \mathrm{a}$ & $47,60 \mathrm{~b}$ \\
\hline
\end{tabular}

As médias seguidas pelas mesmas letras na linha não diferem entre si pelo teste $\mathrm{F}$ a $5 \%$ de probabilidade.
Considerando-se a ausência de efeito das doses de $\mathrm{Ni}$ aplicadas, sobre os teores foliares de $\mathrm{N}$ e de $\mathrm{Ni}$, e o efeito observado no teor desses elementos nas sementes (Figuras 1 e 3), provavelmente, boa parte do $\mathrm{Ni}$ aplicado foi translocado para as sementes do feijoeiro, principalmente nas doses baixas, o que contribuiu para um menor crescimento da parte aérea.

Tabela 6. Desdobramento da interação Ni x Mo para a altura da planta do feijoeiro comum cv. Ouro Vermelho, em função da aplicação de Ni e Mo via foliar. Alegre, ES - 2011

\begin{tabular}{llc}
\hline \multirow{2}{*}{$\begin{array}{l}\text { Doses de Ni } \\
\left(\mathbf{g ~ h a}^{-1}\right)\end{array}$} & \multicolumn{2}{c}{ Mo $\left(\mathbf{g ~ h a}^{-1}\right)$} \\
\cline { 2 - 3 } & \multicolumn{1}{c}{$\mathbf{0}$} & $\mathbf{8 0}$ \\
\hline 0 & $78,00 \mathrm{a}$ & $72,75 \mathrm{a}$ \\
15 & $66,00 \mathrm{~b}$ & $77,25 \mathrm{a}$ \\
30 & $66,25 \mathrm{~b}$ & $74,33 \mathrm{a}$ \\
45 & $76,00 \mathrm{a}$ & $66,33 \mathrm{~b}$ \\
60 & $71,00 \mathrm{a}$ & $71,50 \mathrm{a}$ \\
\hline
\end{tabular}

As médias seguidas pelas mesmas letras na linha não diferem entre si pelo teste $\mathrm{F}$ a $5 \%$ de probabilidade.

Tabela 5. Massa seca de raiz (MSR), número de sementes por vagem (NGV), número de vagens por planta (NVP), massa de sementes (MS) e número de nódulos (NOD) do feijoeiro comum cv. Ouro Vermelho em resposta à adubação molíbdica. Alegre- ES, 2011

\begin{tabular}{lccccc}
\hline $\begin{array}{l}\text { Dose } \\
\text { de Mo }\end{array}$ & $\begin{array}{c}\text { MSR } \\
(\mathbf{g})\end{array}$ & NGV & NVP & $\begin{array}{c}\text { MS } \\
(\mathbf{g})\end{array}$ & NOD \\
\hline 0 & $5,92 \mathrm{a}$ & $4,60 \mathrm{a}$ & $17,85 \mathrm{a}$ & $23,17 \mathrm{a}$ & $148 \mathrm{~b}$ \\
80 & $5,44 \mathrm{a}$ & $4,77 \mathrm{a}$ & $18,20 \mathrm{a}$ & $24,39 \mathrm{a}$ & $180 \mathrm{a}$ \\
\hline Média & 5,68 & 4,685 & 18,02 & 23,78 & 164 \\
\hline CV $(\%)$ & 17,06 & 11,55 & 13,50 & 12,59 & 15,64 \\
\hline
\end{tabular}

As médias seguidas pelas mesmas letras na coluna não diferem entre si pelo teste $\mathrm{F}$ a $5 \%$ de probabilidade.

\section{CONCLUSÕES}

A aplicação foliar de Mo reduziu os teores foliares de $\mathrm{P}, \mathrm{Fe}$ e Ni e aumentou o teor foliar de Mo.

A aplicação foliar de Ni e Mo aumentou os teores de N e de proteína bruta na semente. A aplicação foliar de $\mathrm{Ni}$ elevou em $24,4 \%$ o teor de Ni na semente. A aplicação de Mo promoveu incremento de $315,15 \%$ no teor de Mo na semente.

A aplicação de Mo aumentou em 21,62\% o número de nódulos.

\section{REFERÊNCIAS}

Barbosa GF, Arf O, Nascimento MS, Buzetti S \& Freddi OS (2010) Nitrogênio em cobertura e molibdênio foliar no feijoeiro de inverno. Acta Scientiarum Agronomy, 32:117-123.

Bataglia OC, Furlani AMC, Teixeira JPF, Furlani PR \& Gallo JR (1983) Métodos de Análise Química de Plantas. Campinas, Instituto Agronômico. 48p. (Boletim Técnico, 78).
Biscaro GA, Freitas Júnior NA, Soratto RP, Kikuti H, Goulart Júnior SAR \& Aguirre WM (2011) Nitrogênio em cobertura e molibdênio via foliar no feijoeiro irrigado cultivado em solo de cerrado. Acta Scientiarum Agronomy, 33:665-670.

Braga JM \& Defelipo BV (1974) Determinação espectrofotométrica de P em extratos de solo e material vegetal. Revista Ceres, 21:73-85.

Calonego JC, Ramos Júnior EU, Barbosa RD, Leite GHP \& Filho HG (2010) Adubação nitrogenada em cobertura no feijoeiro com suplementação de molibdênio via foliar. Ciência e Agrotecnologia, 41:334-340.

Campanharo M (2010) Resposta do feijoeiro à aplicação de níquel. Tese de Doutorado. Universidade Estadual Norte Fluminense, Campos dos Goytacazes, RJ, 138p.

Companhia Nacional De Abastecimento. Safras 2011/2012: $12^{\circ}$ levantamento. Disponível em: <http://www.conab.gov.br/ O 1 a 1 a C M S / u p 1 o a d s / a r q u i v o s / 12_09_06_09_18_33_boletim_graos_-_setembro_2012.pdf $>$. Acessado em: 10 Novembro de 2012.

Dixon NE, Gazzola C, Blakeley RL \& Zerner B (1975) Jack bean urease (EC 3.5.1.5), a metalloenzyme. A simple biological role for nickel? Journal of the American Chemistry Society, 97:4131-4133. 
Ferreira ACB, Araújo GAA, Cardoso AA, Fontes PCR \& Vieira C (2002) Influência do molibdênio contido na semente e da sua aplicação foliar sobre a composição mineral de folhas e sementes do feijoeiro. Revista Ceres, 49:443-452.

Ferreira ACB, Araújo GAA, Cardoso AA, Fontes PCR \& Vieira C (2003) Características agronômicas do feijoeiro em função do molibdênio contido na semente e da sua aplicação via foliar. Acta Scientiarum Agronomy, 25:65-72.

Guareschi RF \& Perin A (2008) Efeito do molibdênio nas culturas da soja e feijão via adubação foliar. Global Science and Technology, 2:08-15.

Jasmim JM, Monnerat PH \& Rosa RCC (2002) Efeito da omissão de N, Ni, Co e S sobre os teores de N e S em feijoeiro. Revista Brasileira de Ciência do Solo, 26:967-975.

Jacob Neto J \& Franco AA (1986) Adubação de molibdênio em feijoeiro. Seropédica, Embrapa. 3p. (Comunicado Técnico).

Jacob-Neto J \& Rossetto CAV (1998) Concentração de nutrientes nas sementes: o papel do molibdênio. Floresta e Ambiente, 5:171183.

Klucas RV, Hanus FJ, Russell SA \& Evans HJ (1983) Nickel, a micronutrient for hydrogen dependent growth of Rhizobium japonicum and for expression of urease activity in soybean leaves. Proceedings of the National Academy of Sciences of USA, 80:2253-2257.

Kubota FY, Neto ACA, Araujo AP \& Teixeira MG (2008) Crescimento e acumulação de nitrogênio de plantas de feijoeiro originadas de sementes com alto teor de molibdênio. Revista Brasileira de Ciência do Solo, 32:1635-1641.

Leal RM \& Prado R de M (2008) Desordens nutricionais no feijoeiro por deficiência de macronutrientes, boro e zinco. Revista Brasileira de Ciências Agrárias, 3:301-306.

Leite UT, Araújo GAA, Miranda GV, Vieira RF \& Pires AA (2009) Influência do conteúdo de molibdênio na qualidade fisiológica da semente de feijão: cultivares Novo Jalo e Meia-Noite. Revista Ceres, 56:225-231.

Malavolta E, Vitti GC \& Oliveira SA (1997) Avaliação do estado nutricional de plantas: princípios e aplicações. $2^{\mathrm{a}}$ ed. Piracicaba, Potafos. 319p.

Malavolta E, Moraes MF de, Lavres Junior J \& Malavolta M (2006) Micronutrientes em metais pesados - essencialidade e toxidez, p.117-154. In: Paterniani E (Ed.) Ciência, agricultura e sociedade. Brasília, EMBRAPA Informação Tecnológica. 503p.
Nascimento MS, Arf O \& Silva MG (2004) Resposta do feijoeiro à aplicação de nitrogênio em cobertura e molibdênio via foliar. Acta Scientiarum Agronomy, 26:153-159.

Nascimento MS, Arf O, Barbosa GF, Buzetti S, Nascimento RS \& Castro RM (2009) Nitrogênio em cobertura e molibdênio via foliar em feijoeiro de inverno no sistema plantio direto. Scientia Agraria, 10:351-358.

Oliveira AJ de, Garrido WE, Araújo JD de \& Lourenço S (Coord.) (1991). Métodos de pesquisa em fertilidade do solo. Brasília; Embrapa/SEA. 392p. (Documento $n^{\circ} 03$ )

Pessoa ACS, Ribeiro AC, Chagas JM \& Cassini STA (2000) Concentração foliar de molibdênio e exportação de nutrientes pelo feijoeiro "Ouro Negro" em resposta à adubação foliar com molibdênio. Revista Brasileira de Ciência do Solo, 24:75-84.

Pessoa ACS, Ribeiro AC, Chagas JM \& Cassini STA (2001) Atividades de nitrogenase e redutase de nitrato e redutase de nitrato e produtividade do feijoeiro "Ouro Negro" em resposta à adubação foliar com molibdênio. Revista Brasileira de Ciência do Solo, 25:217-224.

Pires AA, Araújo GAA, Leite UT, Zampirolli PD, Ribeiro JMO \& Meireles RC (2005) Parcelamento e época de aplicação foliar do molibdênio na composição mineral das folhas do feijoeiro. Acta Scientiarum Agronomy, 27:25-31.

Pires AA, Leite UT, Araújo GA de A, Ferreira AC de B \& Ribeiro JMO (2002) Acúmulo de Mo e de N pelo feijoeiro, cv. Manteigão Fosco 11, em resposta a doses crescentes de Mo. In: $7^{\circ}$ Congresso Nacional de Pesquisa de Feijão, Viçosa. Anais, UFV. p.681684 .

Rocha PRR, Araújo GAA, Carneiro JES, Cecon PR \& Lima TC (2011) Adubação molíbdica na cultura do feijão nos sistemas de plantio de plantio direto e convencional. Revista Caatinga, 24:09-17.

Silva MV, Andrade MJB, Moraes AM \& Alves VG (2003) Fontes e doses de molibdênio via foliar em duas cultivares e feijoeiro. Ciência e Agrotecnologia, 27:126-133.

Tedesco MJ, Volkweiss SJ \& Bohnen H (1985) Análises de solo, plantas e outros materiais. Porto Alegre, Universidade Federal do Rio Grande do Sul. 188p. (Boletim Técnico, 5). 